\title{
Practices of Metadata Use in Research Information Management Systems
}

\author{
Dong Joon Lee \\ Texas A\&M University \\ 5000 TAMU, \\ College Station, TX \\ djlee@tamu.edu
}

\author{
Besiki Stvilia \\ Florida State University \\ 142 Collegiate Loop, \\ Tallahassee, FL \\ bstvilia@fsu.edu
}

\author{
Shuheng Wu \\ Queens College, The City \\ University of New York \\ 65-30 Kissena Blvd., Queens, NY \\ Shuheng.Wu@qc.cuny.edu
}

\begin{abstract}
This poster reports on a study that examines the practices of metadata use in a research information management (RIM) system ResearchGate. Understanding these practices can help institutional repositories to better align their RIM metadata models with researchers' needs and priorities. The study identified three categories of RIM system users. The study's preliminary findings suggest that community members are more willing to share their personal information and provide full-texts of their works on ResearchGate compared to readers and personal record managers.
\end{abstract}

\section{Keywords}

Research information management, metadata, ResearchGate, institutional repositories.

\section{INTRODUCTION}

Many institutions actively develop and implement their local research information management (RIM) systems for various purposes. RIM systems support various stakeholder groups, including researchers, funders, university administrators, librarians, and aggregators (SmithYoshimura et al., 2014; Wu, Stvilia, \& Lee, 2016). Each of these groups can use RIM metadata for different purposes and assign different levels of importance in different activities. Thus, to facilitate research identity data use and to engage researchers in its curation, it is important to identify the stakeholders' value structures and priorities for different research identity data elements, and align RIM data structures and quality assurance activities with those priorities. The purpose of this study was to examine researchers' practices of using metadata elements in RIM systems. The findings can be used to develop a value model of RIM metadata elements (Stvilia \& Gasser, 2008), which can help institutional repositories to better align their RIM metadata models with researchers' needs and priorities.

[This is the space reserved for copyright notices.]

ASIST 2017, Washington, DC | Oct. 27-Nov 1, 2017

[Author Retains Copyright. Insert personal or institutional copyright notice here.]

\section{METHODOLOGY}

This poster reports on part of a larger study, which examined researchers' use of and engagement with RIM systems. The study's design included 15 qualitative semistructured interviews and a survey completed by 412 researchers representing 80 universities in the US classified as high research universities in the Carnegie Classification of Institutions of Higher Education. Detailed reports of findings from the interviews and survey can be found elsewhere (Wu, Stvilia, \& Lee, 2017). The findings of this poster were based on a content analysis on metadata elements of ResearchGate and an empirical analysis where the authors analyzed the use of metadata elements in the ResearchGate profiles of 126 researchers (see Figure 1), sampled from the survey participants. Based on their participation levels in ResearchGate, the sample consists of 26 readers, 50 personal record managers, and 50 community members. One of the authors manually examined ResearchGate to assemble an aggregate set of metadata elements provided there. This study addressed the following research questions: (1) What metadata elements does ResearchGate provide to support researchers' activities? (2) What metadata elements do researchers use in their ResearchGate profiles?

\section{FINDINGS}

The analysis of ResearchGate's metadata elements produced an aggregated set of user-editable metadata elements typified by nine different categories representing researchers' academic-related activities (see Figure 3). To answer the second research question, the authors examined 126 researchers' ResearchGate profiles from the sample. Figure 2-A presents the frequencies of uses of metadata categories in the sample. Most researchers' ResearchGate

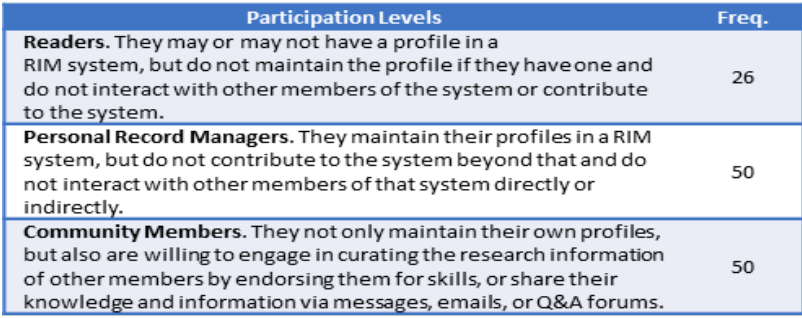

Figure 1. Distribution of the sample by participation level. 

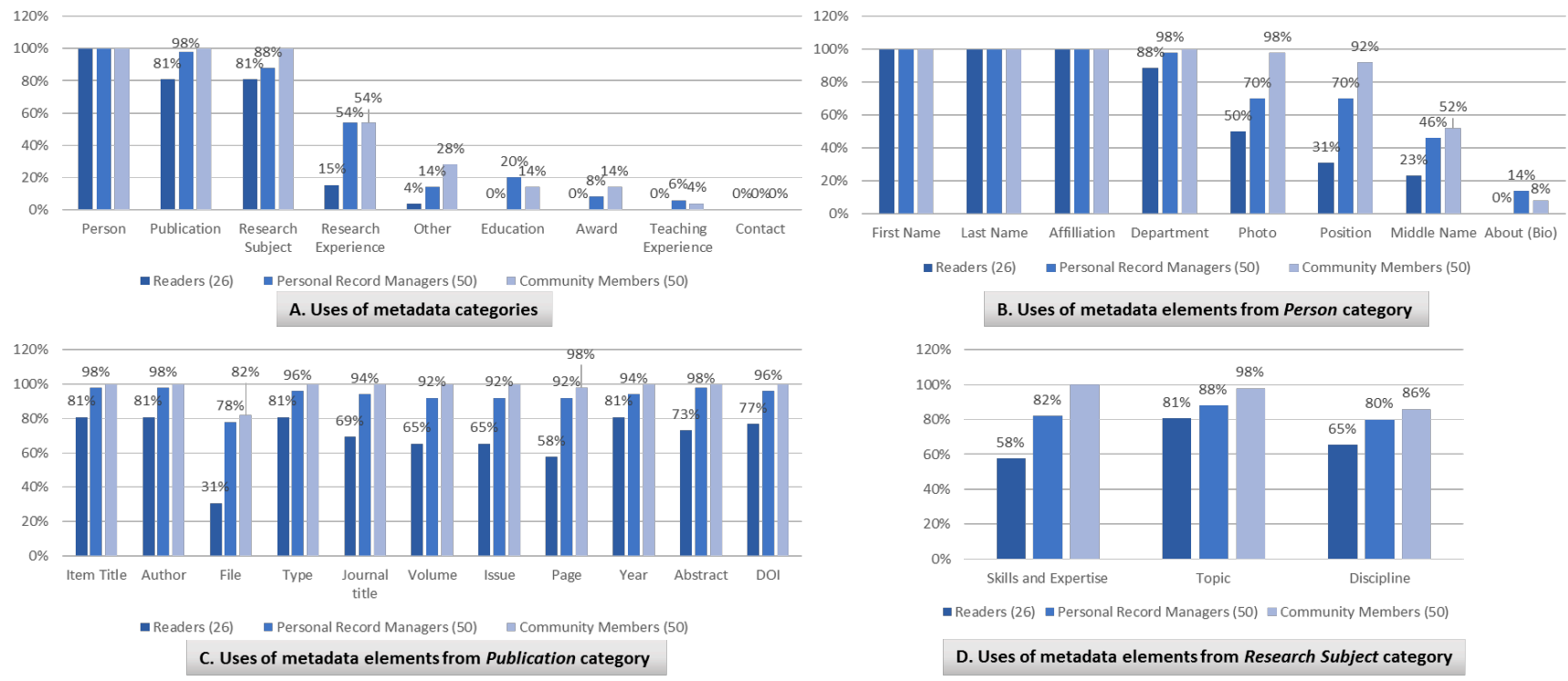

Figure 2. Use of metadata categories and metadata elements from different categories.

profiles used at least one element from the categories of person, publication, and research subject. Since almost all researchers' profiles used metadata elements from the person, publication, and research subject categories, the authors next investigated the use of individual elements within these categories. Figure 2-B summarizes the uses of specific metadata elements from the person category. More than $90 \%$ of the community members' profiles included first name, last name, affiliation, department, photo, and position. This indicates that they are more willing to share their personal information than readers and personal record managers. All of the elements from the publication category were highly used except that file was occasionally used by readers (see Figure 2-C). This indicates that compared to readers, community members and personal record managers are more willing to provide full-texts of their works (downloadable files) on ResearchGate. Similarly, community members are more likely to share

\begin{tabular}{|c|c|}
\hline Categories & Metadata Elements \\
\hline Person & $\begin{array}{l}\text { First name, Middle name, Last name, Alternative first name, Alternative middle } \\
\text { name, Alternative last name, Degree, Institution, Department, Position, Time } \\
\text { period, Gender, Email address, Profile photo, Time zone, About }\end{array}$ \\
\hline Publication & $\begin{array}{l}\text { Publication title, Author, File, Type (i.e., book, chapter, code, conference paper, } \\
\text { method, patent, poster, proposal, technical report, thesis, working paper), } \\
\text { Journal referee, Volume, Issue, Page, Day, Month, Year, Topic, Abstract, DOI, } \\
\text { Publisher, Editor, Edition, ISBN, Chapter, Book title, Description, Language(s), } \\
\text { Repository link, License, Ref. Number, Ordinal, Grant number, Report number, } \\
\text { Supervisor, Degree, Version number, State }\end{array}$ \\
\hline $\begin{array}{l}\text { Research } \\
\text { subject }\end{array}$ & Topic, Skills \& Expertise, Discipline \\
\hline $\begin{array}{l}\text { Research } \\
\text { experience }\end{array}$ & $\begin{array}{l}\text { Position, Institution, Department, Research group, Time period, Location, } \\
\text { Description }\end{array}$ \\
\hline $\begin{array}{l}\text { Teaching } \\
\text { experience }\end{array}$ & Position, Institution, Department, Time periad, Location, Description \\
\hline Education & Institution, Field of study, Degree, Time period, Location \\
\hline Award & $\begin{array}{l}\text { Type (i.e., award, grant, scholarship), Title, Start date, End date, Amount, } \\
\text { Funding agency, Grant reference, Principal investigator, Research institution, } \\
\text { Co-investigator, Secondary institution }\end{array}$ \\
\hline Contact & $\begin{array}{l}\text { Lacation, Website, Phone, Mobile, Fax, Twitter, Skype, Instant messenger, } \\
\text { Birthday, }\end{array}$ \\
\hline Other & Language(s), Scientific society, Journal referee, Other interest, ORCID \\
\hline
\end{tabular}

Figure 3. User-editable metadata categories and elements used in ResearchGate. their disciplines, research topics, and skills and expertise on ResearchGate (see Figure 2-D).

\section{CONCLUSION AND FUTURE RESEARCH}

This poster presents researchers' use of metadata elements in a RIM system. The findings can be used to develop a value model of metadata elements for RIM. Future research will conduct interviews with researchers to learn about their motivations for using specific metadata elements in RIM systems and their perceived values of those elements.

\section{ACKNOWLEDGMENTS}

This research is supported by an OCLC/ALISE Library and Information Research Grant for 2016 and a National Leadership Grant from the IMLS of the U.S. Government (grant \# LG-73-16-0006-16).

\section{REFERENCES}

Smith-Yoshimura, K., Altman, M., Conlon, M., Cristán, A. L., Dawson, L., Dunham, J., ... Woutersen, S. (2014). Registering Researchers in Authority Files. Dublin, Ohio: OCLC Research.

Stvilia, B., Gasser, L. (2008). Value based metadata quality assessment. Library \& Information Science Research, $30(1), 67-74$.

Wu, S., Stvilia, B., \& Lee, D. J. (2016). Exploring researchers' participation in online research identity management systems. In Proceedings of the ASIS\&T. Copenhagen, Denmark, 53(1), 1-6.

Wu, S., Stvilia, B., \& Lee, D. J. (2017). Readers, personal record managers, and community members: An exploratory study of researchers' participation in online research information management systems. Journal of Library Metadata, 17(2), 1-34. 